\title{
In silico cell and tissue science
}

\author{
Liesbet Geris ${ }^{1,2,3^{*}}$ and Fred J Vermolen ${ }^{4^{*}}$
}

The expression "in silico" studies is used to denote these studies that are performed on a computer or via computer simulation. The phrase was coined in 1989 as an analogy to the Latin phrases in vivo, in vitro, and in situ, which are commonly used in biology, and which refer to experiments done in living organisms, outside of living organisms, and where they are found in nature, respectively [1].

Research in the natural sciences, such as biology and medicine (henceforth jointly termed biomedicine), develops through the formulation of hypotheses, which are to be validated by reproducible experiments. The validation of theoretical concepts can only take place once the biological hypotheses have been quantified in terms of mathematically sound relations. The mathematical relations are often formulated in concepts like (partial) differential equations, geometrical relations or stochastic processes, to mention a few of them. In order to simulate the biological processes of interest on the basis of the model concepts, rigorous mathematical techniques should be used or developed. Compared to the intimate cooperation between mathematics and (computational) physics, the field of mathematical and in silico biomedicine is rather new.

In the past decades, in silico biomedicine has often been equaled to bio-informatics, which shows but a fraction of the big in silico biomedicine puzzle. In more recent years, initiatives as the Physiome [2] and the Virtual Physiological Human [3] have done much to advocate a broader view on in silico biomedicine. In silico tools have been and continue to be essential tools to investigate the complexity of physiological processes. Figure 1 shows the classical picture of the various length scales involved in physiological processes. In silico models allow to explicitly describe information moving from

\footnotetext{
*Correspondence: liesbet.geris@ulg.ac.be; F.J.Vermolen@tudelft.nl 'Biomechanics Research Unit, University of Liège, Liège, Belgium ${ }^{4}$ Delft Institute of Applied Mathematics, University of Technology, Delft, The Netherlands

Full list of author information is available at the end of the article
}

one length scale to another, in either direction: upward, being from the gene to the organism, and downward, from the organisms all the way down to the gene [4]. At the center of this scale bar we find the cell and tissue level, levels that are very rich in biological data. In order to obtain, improve and optimize treatments of diseases on the multitude of organs, it is crucially important to understand the biological mechanisms that are play a role in the functioning of the organs. To this extent, understanding collective cell dynamics, such as migration or differentiation, is of vital importance. This insight is fed by knowledge on the cell level, such as motility, cellular sensitivity to chemical and mechanical changes in the environment. The modeling approach starting from these cell and tissue levels and reaching up and down to other levels has been termed the 'middle-out approach' and has been proposed as the optimal strategy for in silico biomedicine, combining the best of the 'bottomup' and 'top-down' approaches [5].

The first appearances of in silico modeling in biomedicine in the literature date back to the beginning of the 21 st century. As it can be observed from Figure 2, the use of in silico models is in full expansion. It is our belief that the time is ripe for the creation of a journal dedicated to this emerging field.

The goal of the journal 'In silico cell and tissue science' is to promote basic and applied in silico research, at both cellular and tissue level, that integrates the expanding knowledge in the fields of biology, mathematics, engineering and their interplay. In particular, contributions are appreciated that

- quantify the physical, biological and chemical environment in which cells and tissues behave and function in healthy conditions and pathological conditions;

- describe and quantify cellular and tissue responses under different environmental conditions and stimulations either from mechanical, chemical or other biophysical origins; 


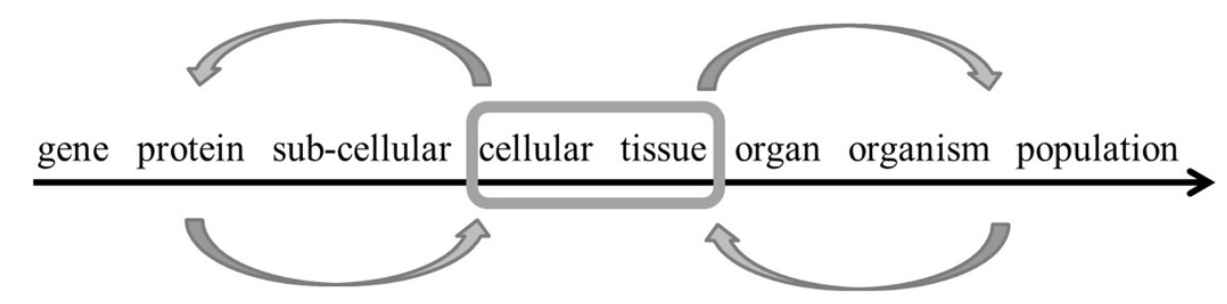

Figure 1 The scales of in silico models with the cell and tissue scale at the center.

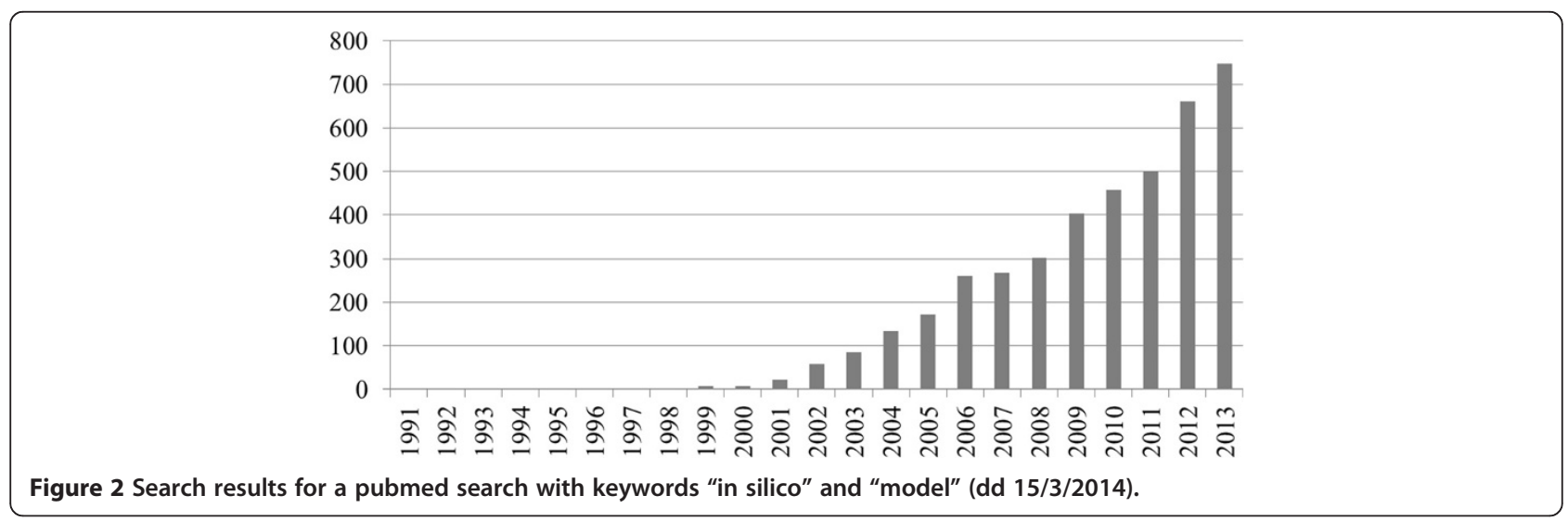

- determine and scrutinize relations between chemical, physical, mechanical and biological processes such as cell growth, division, differentiation, death, migration and tissue growth, remodeling, repair or decay.

Contributions on the nano, micro, and/or macrolevels are welcome. Especially encouraged are analytical and computational models based on physico-biological principles as well as topics on new mathematical methods that facilitate building, analysis, optimization and validation of models of biological systems in both cell and tissue scales. Approaches are predominantly silico based, but can also involve experimental contributions assessing the foundations of cellular and tissue phenomena. Additionally, in silico tools and technologies allowing for the interpretation and exploitation of experimental data (such as the development of virtual histopathology by image analysis) belong to the scope of this journal.

We hope that the creation of the journal of 'In silico cell and Tissue Science' can play a role in the further development and exploitation of the fields of in silico biology and in silico medicine.

\section{Author details}

${ }^{1}$ Biomechanics Research Unit, University of Liège, Liège, Belgium.

${ }^{2}$ Prometheus, Division of Skeletal Tissue Engineering Leuven, KU Leuven, Leuven, Belgium. ${ }^{3}$ Biomechanics Section, KU Leuven, Leuven, Belgium. ${ }^{4}$ Delft Institute of Applied Mathematics, University of Technology, Delft, The Netherlands.
Received: 12 May 2014 Accepted: 12 May 2014

Published: 23 October 2014

\section{References}

1. Wikipedia Search term "in silico". http://en.wikipedia.org/wiki/In_silico. accessed 15/3/2014

2. The physiome project. http://physiomeproject.org/

3. The VPH Institute. http://www.vph-institute.org/

4. Noble D (2006) The music of life: biology beyond genes. Oxford University Press. ISBN-13: 978-0199295739

5. Noble D (2002) Modeling the heart - from genes to cells to the whole organ. Science 295(5560):1678-1682

doi:10.1186/2196-050X-1-1

Cite this article as: Geris and Vermolen: In silico cell and tissue science. In Silico Cell and Tissue Science 2014 1:1.

\section{Submit your manuscript to a SpringerOpen ${ }^{\circ}$ journal and benefit from:}

- Convenient online submission

Rigorous peer review

- Immediate publication on acceptance

- Open access: articles freely available online

- High visibility within the field

- Retaining the copyright to your article

Submit your next manuscript at $>$ springeropen.com 